\title{
An Analysis of elastic and inelastic lateral torsional buckling of web-tapered I beams using the finite element method
}

\author{
Paulus Karta Wijaya ${ }^{1, *}$, Cecilia Lauw Giok Swan ${ }^{1}$, and Ghassani Sadrina Noor ${ }^{2}$ \\ ${ }^{1}$ Universitas Katolik Parahyangan, Civil Engineering Department, Bandung, Indonesia \\ ${ }^{2}$ Waskita Karya, Jakarta, Indonesia
}

\begin{abstract}
Elastic and inelastic lateral torsional buckling of simply web tapered I beam is studied using the finite element method. The length of the beams is $8000 \mathrm{~mm}$ for elastic lateral torsional buckling and $4000 \mathrm{~mm}$ for inelastic lateral torsional buckling. The depth of cross section at one end is $500 \mathrm{~mm}$ and at the other end it is varied. The thickness of the flange is $16 \mathrm{~mm}$ and the thickness of the web is $10 \mathrm{~mm}$. The section of the beams is compact. The beams are loaded by end moments. The ratio of end moments at one end and the moments at the other end are varied. The beams are assumed to have geometric imperfection and the distribution of imperfection follows the shape of the first buckling mode of elastic lateral torsional buckling of the beam. The amplitude of the imperfection is taken one milimeter at the top flange in lateral direction. The load is increased until the beams collapse. The ultimate load is considered as the critical moments of the beams. The results of the analysis are compared to nominal lateral torsional buckling moments using the method presented in the AISC Design Guide 25 (Design Guide for web tapered members). It can be concluded that usually the critical moments of the collapse analysis are close to the critical moments of the design guide. But sometimes it is less than the design guide and it means design guide is sometimes is not on the safe side.
\end{abstract}

\section{Introduction}

Web tapered steel beams are usually used due to economic aspects. In beam design, one of the consideration is lateral torsional buckling. Study of lateral torsional buckling of web tapered I beams has been made by many researchers. Polyzois [1] studied the modification factor using FEM. The analysis consists of the elastic buckling analysis. Miller [2] studied lateral torsional buckling of web tapered I beams using nonlinear finite element method. J.S Park et al [3] studied lateral torsional buckling of stepped beams using the linear finite element method. Vandermeulen et al [4] studied lateral torsional buckling of tapered beams using the linear and nonlinear finite element method, but residual stress was not considered. Zhang and Tong [5] developed a new theory for lateral torsional buckling of web tapered I beams. They formulated total potential energy for lateral torsional buckling of elastic I beams and used the classical variational principle for buckling analysis. Raftoyiannis and Adamakos [6] developed a simple numerical approach for determining elastic critical lateral torsional buckling. Kovac,M. [7] studied elastic lateral torsional buckling of web tapered I beams using the 1D and 3D FEM method. He developed the 1D element and compared it to the 3D shell element model. Naaim et al [8] studied lateral torsional buckling behaviour of the web tapered section with perforation using the finite element method. Patil [9] studied lateral torsional buckling of web tapered cantilever beams using the finite element method.

This paper presents the results of a study about lateral torsional buckling of web tapered I beams loaded by end moments. The cross section of the beam is the compact section. The method of analysis is the finite element method. The beam, modelled by the finite element method, is loaded by incremental load until they collapse. For the buckling analysis, geometric imperfection of the beams must be introduced. The residual stress is taken into account. The results of analysis are compared with the critical moment computed using the AISC Steel Design Guide 25.

\section{AISC Design Guide 25}

The AISC Design Guide 25 (DG 25) [10] provides a method to design web tapered members. In the design guide, there is a method to evaluate the lateral torsional buckling strength of tapered beams. The procedure is

* Corresponding author: paulusk@unpar.ac.id 
presented briefly in this paper and the result of using this design guide will be compared to the result of the finite element analysis. The method of DG 25 presented here is only for doubly symmetric and compact sections.

First elastic lateral torsional buckling stress, $F_{\text {eLTB }}$, is calculated using equation (1) and section properties at the middle of the unbraced length.

$$
F_{e L T B}=\frac{\pi^{2} E}{\left(L_{b} / r_{t}\right)^{2}} \sqrt{1+0.078 \frac{J}{S_{x} h_{o}}\left(\frac{L_{b}}{r_{t}}\right)^{2}}
$$

$E$ stands for the modulus of elasticity, $L_{b}$ is unbraced length, $r_{t}$ is effective radius gyration for lateral torsional buckling, $J$ is torsional constant, $S_{x}$ is section modulus about strong axis, $h_{o}$ is distance between flange centroids.

Determine the location of maximum compressive flexural stress, $f_{r \max }$, within the unbraced length. At this location, calculate the nominal buckling stress multiplier, $\gamma_{\text {eLTB }}$ which is equal to $F_{\text {eLTB }} / f_{r \max }$. Calculate the nominal moment, $\mathrm{M}_{\mathrm{n}}$, at various location along the unbraced length using the following equation

If $\frac{\left(\gamma_{e L T B}\right) f_{r}}{F_{y}} \geq \frac{\pi^{2}}{1.1}=8.2$ the lateral torsional buckling limit state does not apply.

If $8.2 \succ \frac{\left(\gamma_{e L T B}\right) f_{r}}{F_{y}} \geq 0.7$ calculate the nominal lateral torsional buckling strength

$$
\begin{gathered}
M_{n}=M_{p}-0.3767\left(M_{p}-0.7 F_{y} S_{x}\right) \\
\left(\pi \sqrt{\frac{F_{y}}{\left(\gamma_{e L T B}\right) f_{r}}}-1.1\right)
\end{gathered}
$$

$$
\begin{aligned}
& \text { If } \frac{\left(\gamma_{e L T B}\right) f_{r}}{F_{y}} \prec 0.7 \\
& \qquad M_{n}=C_{b}\left(\gamma_{e L T B}\right) f_{r} S_{x}
\end{aligned}
$$

$C_{b}$ is the lateral torsional buckling modification factor for nonuniform moment diagram, $f_{r}$ is flexural stress at the location considered.

\section{Problem statement}

The problem considered is a simply supported beam as illustrated in Figure 1. The beam is web tapered. Torsional rotation at the ends of the beam is restrained but warping is allowed. The loads are end moments. The bending moment in the beam is a positive single curvature (upper flange is in compression). The ratio between the right end moment to the left end moment is varied.

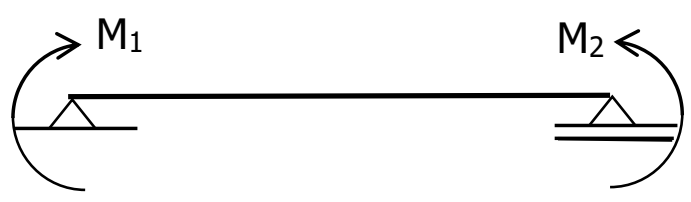

Fig. 1. The beam considered.

\section{Finite element model}

\subsection{Geometrical model}

The beam is modelled by shell element as is illustrated in Fig.2. The element is four node element with six degrees of freedom per node, three translations and three rotations. A Cartesian coordinate is shown in the figure. At one end of the beam, the node at centroid is restrained in three translation directions and the other nodes are free at $\mathrm{x}$ direction and restrained at $\mathrm{y}$ and $\mathrm{z}$ directions. At the other end of the beam, all nodes are restrained at $y$ and $\mathrm{z}$ directions and free at $\mathrm{x}$ direction. These boundary conditions are used to accommodate warping at the boundary.

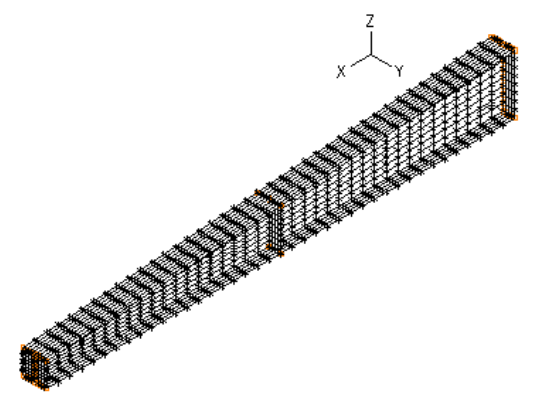

Fig. 2. Finite element model of a web-tapered beam

\subsection{Material model}

The material is modelled as a plastic multi linier material model. Yield stress, $F_{y}$, is $250 \mathrm{MPa}$ and the tensile strength is $410 \mathrm{MPa}$. The stress-strain relation is modelled as piecewise linear as shown in Figure 3.

Residual stress is taken into account. Distribution of the residual stress is linear and the maximum residual stress is 0,3 yield stress as shown in Fig. 4 . In the finite element analysis the section element is divided into 8 parts for the flange and 8 parts for the web. Residual stress is modelled as constant at each part as shown at Fig. 5. To take into account the residual stress, the yield stress and tensile strength are superposed according the stress due to loading. Due to loading, the top flange is in compression, the yield stress for each part is modified by substracting yield stress of the material by the residual stress at each part. For the bottom flange, the yield stress of each part is modified by adding yield stress of the material by residual stress of each part. 


\subsection{Loading model}

The end moments are modelled as point loads at nodes at flanges and at the end of the beam. The loads at the upper flanges are the same in magnitude but in opposite direction of the load at the lower flanges. The end moment is the total load at the upper flange multiplied by the distance between flange centroids. The ratio of the right end moment to the left end moment is varied.

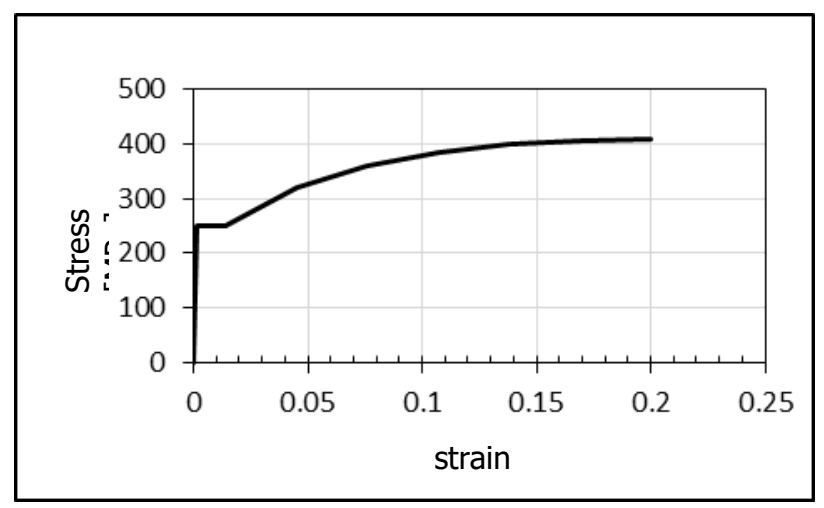

Fig. 3. Stress - strain diagram used in the analysis.

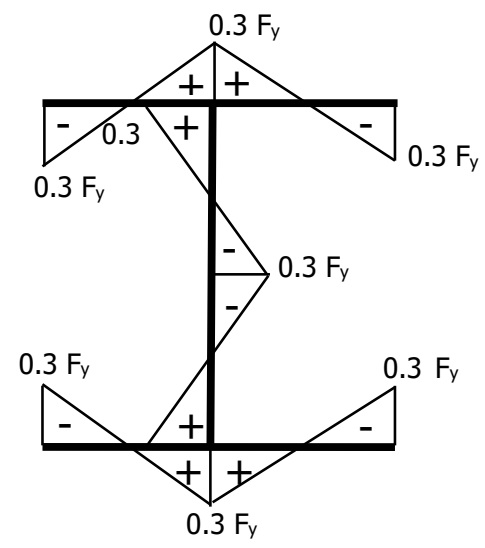

Fig. 4. Residual stress distribution.

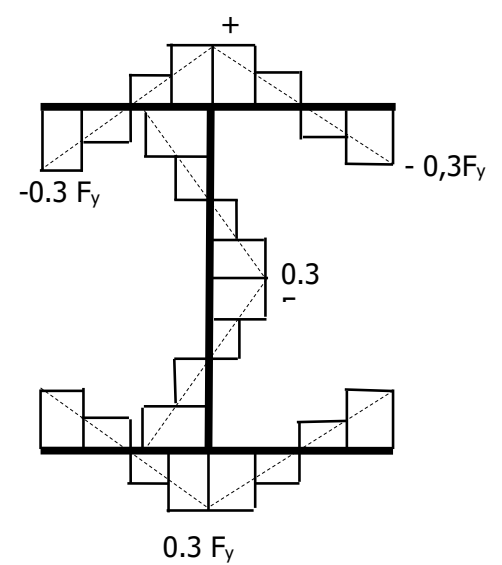

Fig. 5. Model of residual stress for finite element analysis.

\section{Collapse analysis}

The analysis consists of the nonlinear incremental load method and is called collapse analysis. The analysis is performed using the ADINA program. In collapse analysis, the structure is given displacement control loading. The nodal displacement at the loaded nodes are increased gradually with small increments and the nodal forces are computed for each step until the beam collapses. For buckling analysis, before the collapse analysis is performed, the beam is given geometric imperfection. The shape of distribution of geometric imperfection is taken as the first buckling mode computed by the linear buckling analysis. Linear buckling analysis is the Eigen value buckling analysis. The amplitude of imperfection is taken to be $1 \mathrm{~mm}$ in lateral direction at the middle of the top flange. After the analysis, nodal load - lateral deflection curve will be obtained. The maximum load is interpreted as the critical load of the beam. Figure 6 shows the shape of deformation after the collapse analysis is completed.

\section{Verification of finite element method}

Two prismatic beams are analysed using collapse analysis for verification of the method. The length of the first beam is $8000 \mathrm{~mm}$ and the length of the second one is $4000 \mathrm{~mm}$. Both of the beams are WF500x200x10x16. Figure 6 shows the displacement of the beam with an 8000 span at the end of analysis. Figure 7 shows the curve of nodal load versus lateral displacement at the middle of top flange the beam with an $8000 \mathrm{~mm}$ span and Figure 8 shows the curve for beam with a $4000 \mathrm{~mm}$ span. In Figure 7 and Figure 8, the load is the load at one loaded node. The maximum load is considered as the critical load and the critical moment is computed using this critical load.

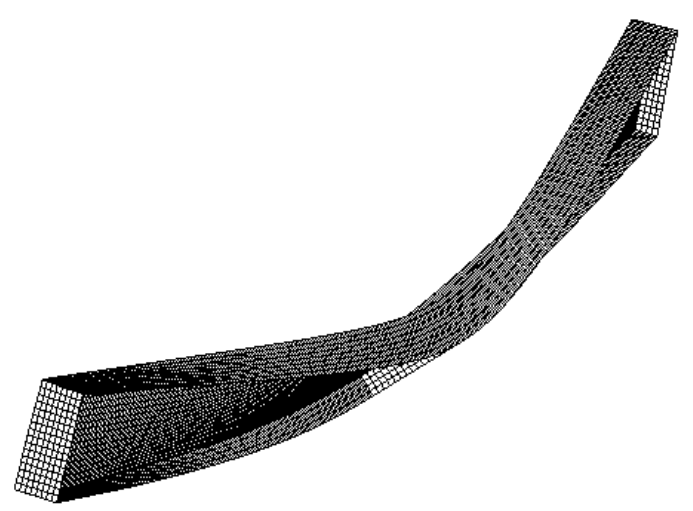

Fig. 6. Displacement of the beam at the end of collapse analysis. 


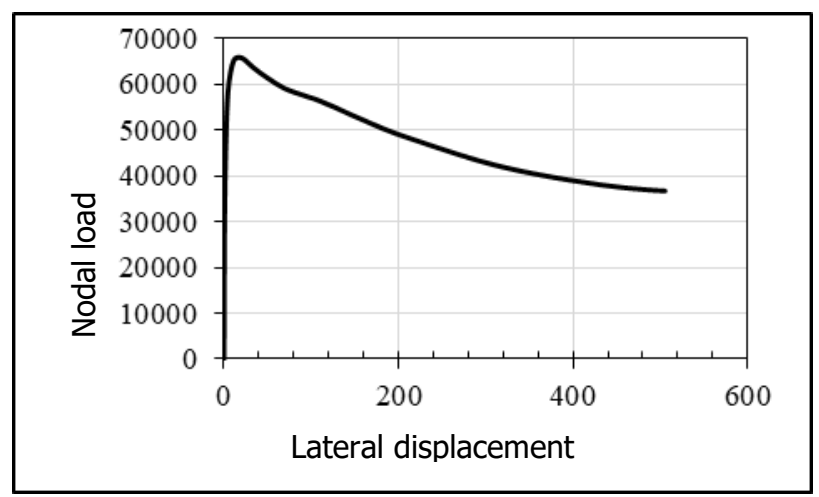

Fig. 7. Nodal load vs lateral nodal displacement at the middle of the top flange of the prismatic beam with $8000 \mathrm{~mm}$ span

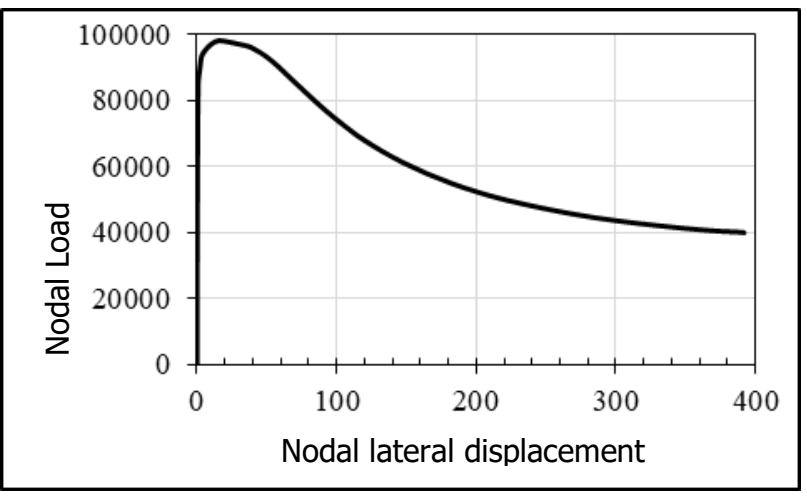

Fig. 8. Nodal load vs lateral nodal displacement at the middle of the top flange of the prismatic beam with $4000 \mathrm{~mm}$ span.

Table 3. Mcr elastic analytical vs $M_{\text {cr }}$ elastic finite element.

\begin{tabular}{|c|c|c|c|}
\hline $\mathrm{L}$ & $M_{\text {cr }}$ elastic & Mcr $_{\text {cr }}$ elastic FEM & difference \\
\hline 8000 & $247854.7 \mathrm{~N}-\mathrm{m}$ & $268794.2 \mathrm{~N}-\mathrm{m}$ & $8.45 \%$ \\
\hline 4000 & $742887.0 \mathrm{~N}-\mathrm{m}$ & $698508.8 \mathrm{~N}-\mathrm{m}$ & $-5.97 \%$ \\
\hline
\end{tabular}

Table 4. Mcr AISC vs Mcr collapse analysis.

\begin{tabular}{|c|c|c|c|}
\hline $\mathrm{L}$ & $\mathrm{M}_{\mathrm{cr}}$ AISC & $\mathrm{M}_{\mathrm{cr}}$ inelast FEM & difference \\
\hline 8000 & $247854.7 \mathrm{~N}-\mathrm{m}$ & $254417.1 \mathrm{~N}-\mathrm{m}$ & $2.65 \%$ \\
\hline 4000 & $444026.58 \mathrm{~N}-\mathrm{m}$ & $379810 \mathrm{~N}-\mathrm{m}$ & $-14.46 \%$ \\
\hline
\end{tabular}

In Table 3, the elastic critical moment computed by linear buckling FEM (finite element method) is compared to the analytical critical moment. The difference is $8.45 \%$ for $8000 \mathrm{~mm}$ span beam and $-5.97 \%$ for $4000 \mathrm{~mm}$ beam. The difference is below $10 \%$. It can be concluded that the result for linear buckling has sufficiently converged.

In Table 4 the critical moment computed from the collapse analysis is compared to the nominal moment from the AISC equations. The difference is $2.65 \%$ for $8000 \mathrm{~mm}$ beam and $-14.46 \%$ for $4000 \mathrm{~mm}$ beam. For the long beam the failure is elastic buckling and the AISC formula for this is an exact solution of the differential equation and the result of collapse analysis is very good. For the $4000 \mathrm{~mm}$ beam, the difference is $-14,46 \%$ but the AISC formula for this is not an exact solution, so it cannot be used as verification. From Table 3 and 4, it is concluded that the model for collapse analysis can be used for buckling analysis.

\section{Result of analysis}

There are two series of beams. The span of the first beam is $8000 \mathrm{~mm}$ and the span of the second beam is 4000 $\mathrm{mm}$. The depth of the left end cross section is $500 \mathrm{~mm}$ and the right end cross section is varied. The flange width is $200 \mathrm{~mm}$, the thickness of the flange is $16 \mathrm{~mm}$ and the thickness of the web is $10 \mathrm{~mm}$. Left end moment is $\mathrm{M}_{1}$ and right end moment is $\mathrm{M}_{2}$. The ratio of end moments $\mathrm{M}_{2} / \mathrm{M}_{1}$ is varied. The name of the beam model with the right depth end cross section and ratio of the end moments is shown at Table 3 for beams with an 8 meter span and Table 4 for beams with is a 4 meter span.

Table 3. Beams with $8000 \mathrm{~mm}$ span.

\begin{tabular}{|c|c|c|}
\hline $\begin{array}{l}\text { Name of } \\
\text { beam }\end{array}$ & $\begin{array}{c}\text { Right depth } \\
(\mathrm{mm})\end{array}$ & $\mathrm{M}_{2} / \mathrm{M}_{1}$ \\
\hline 1 1-A-1 & 400 & 1 \\
\hline $1-\mathrm{A}-2$ & 400 & $4 / 5$ \\
\hline $1-\mathrm{A}-3$ & 400 & $3 / 5$ \\
\hline $1-\mathrm{A}-4$ & 400 & $1 / 2$ \\
\hline $1-\mathrm{A}-5$ & 400 & 0 \\
\hline $1-\mathrm{B}-1$ & 300 & 1 \\
\hline $1-\mathrm{B}-2$ & 300 & $4 / 5$ \\
\hline $1-\mathrm{B}-3$ & 300 & $3 / 5$ \\
\hline $1-\mathrm{B}-4$ & 300 & $1 / 2$ \\
\hline $1-\mathrm{B}-5$ & 300 & 0 \\
\hline $1-\mathrm{C}-1$ & 200 & 1 \\
\hline $1-\mathrm{C}-2$ & 200 & $4 / 5$ \\
\hline $1-\mathrm{C}-3$ & 200 & $3 / 5$ \\
\hline $1-\mathrm{C}-4$ & 200 & $1 / 2$ \\
\hline $1-\mathrm{C}-5$ & 200 & 0 \\
\hline
\end{tabular}


Table 4. Beams $4000 \mathrm{~mm}$ length.

\begin{tabular}{|c|c|c|}
\hline $\begin{array}{l}\text { Name of } \\
\text { beam }\end{array}$ & Right depth & $\mathrm{m} / \mathrm{M}$ \\
\hline $2-\mathrm{A}-1$ & 400 & 1 \\
\hline $2-\mathrm{A}-2$ & 400 & $4 / 5$ \\
\hline $2-\mathrm{A}-3$ & 400 & $3 / 5$ \\
\hline $2-\mathrm{A}-4$ & 400 & $1 / 2$ \\
\hline $2-\mathrm{A}-5$ & 400 & 0 \\
\hline $2-\mathrm{B}-1$ & 300 & 1 \\
\hline $2-\mathrm{B}-2$ & 300 & $4 / 5$ \\
\hline $2-\mathrm{B}-3$ & 300 & $3 / 5$ \\
\hline $2-\mathrm{B}-4$ & 300 & $1 / 2$ \\
\hline $2-\mathrm{B}-5$ & 300 & 0 \\
\hline $2-\mathrm{C}-1$ & 200 & 1 \\
\hline $2-\mathrm{C}-2$ & 200 & $4 / 5$ \\
\hline $2-\mathrm{C}-3$ & 200 & $3 / 5$ \\
\hline $2-\mathrm{C}-4$ & 200 & $1 / 2$ \\
\hline $2-\mathrm{C}-5$ & 200 & 0 \\
\hline
\end{tabular}

After collapse analysis is completed, the loaddisplacement curve can be drawn.

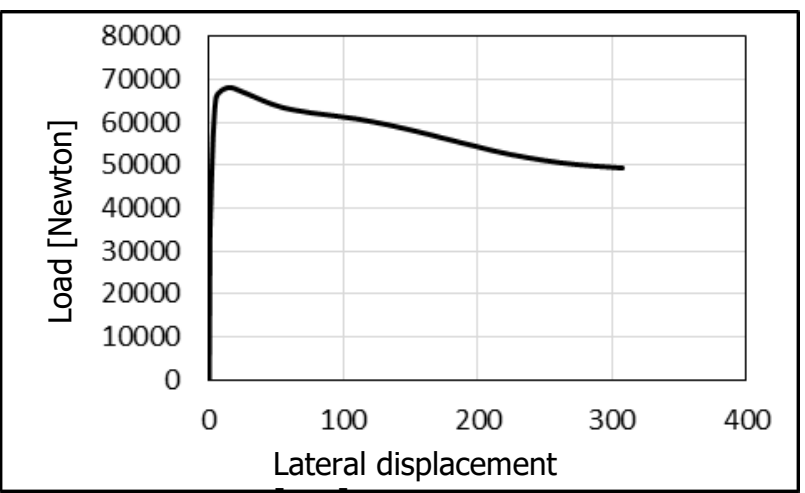

Fig. 9. Nodal load at a node at the end of the beam vs lateral displacement at the middle of the top flange of the 1-C-4 beam.

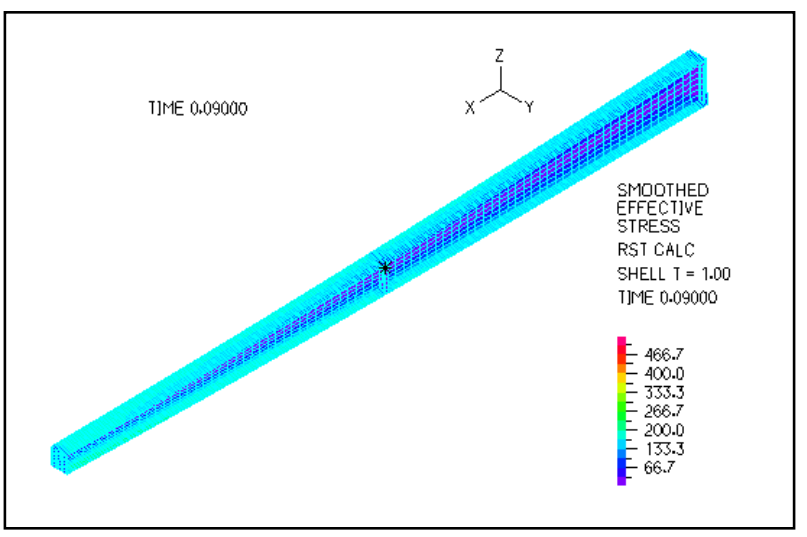

Fig. 10. Stress distribution of the 1-C-4 beam at the peak load (stress in $\mathrm{MPa}$ )
Figure 9 shows the nodal load at the end of the beam versus lateral displacement at the middle of the top flange of beam 1-C-4. The peak load is $65827.2 \mathrm{~N}$, occurred at y displacement $13.7 \mathrm{~mm}$

Figure 10 shows stress distribution in beam 1-C-4 at the peak load. It can be seen that the stress is in the elastic range. It confirms that the use of elastic buckling formula is correct.

Figure 11 shows the nodal load at the end of the beam versus lateral displacement at the middle of top flange for beam 2-C-4. The peak load is $91093 \mathrm{~N}$, occurred at a y displacement of $22.93 \mathrm{~mm}$.

It is interesting to observe that lateral displacement for the 8 meter beam is smaller than for the 4 meter beam at their peak load.

Figure 12 shows stress distribution in beam 2-C-4 at the peak load. It can be seen that at the flange the stress is in inelastic range and the web is still in elastic range.

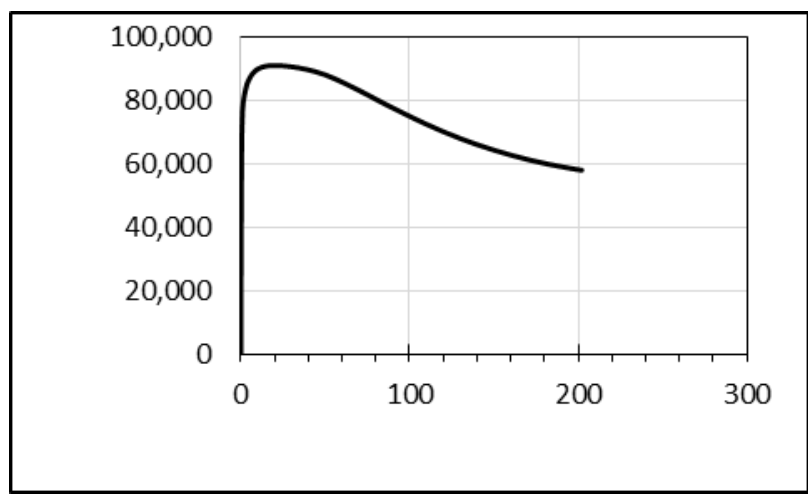

Fig. 11. Nodal load at the end of the beam vs lateral displacement at the middle of the top flange of the 2-C-4 beam.

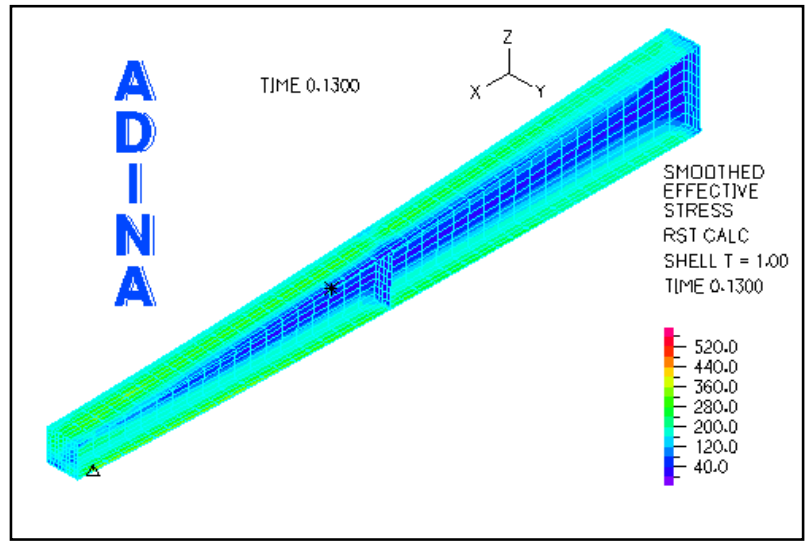

Fig. 12. Stress distribution of the $2-\mathrm{C}-4$ beam at the peak load

The results of all analyses are tabulated in Table 5 for beams with an $8000 \mathrm{~mm}$ span and Table 6 for beams with a $4000 \mathrm{~mm}$ span. The Tables also show the difference between the critical moment from collapse analysis and DG-25. 
Table 5. Analysis result of beams with an $8000 \mathrm{~mm}$ span

\begin{tabular}{|c|c|c|c|c|}
\hline Beam & $\begin{array}{c}\text { End } \\
\text { moment } \\
\text { Ratio }\end{array}$ & Collapse & DG-25 & $\begin{array}{c}\text { Difference } \\
{[\%]}\end{array}$ \\
\hline $1-A-1$ & 1 & 230462400 & 238079609 & 3.3 \\
\hline $1-A-2$ & 0.8 & 256316800 & 257992082 & 0.7 \\
\hline $1-A-3$ & 0.6 & 287596800 & 289413623 & 0.6 \\
\hline $1-A-4$ & 0.5 & 305527600 & 307297656 & 0.6 \\
\hline $1-A-5$ & 0 & 394435600 & 466586941 & 18.3 \\
\hline $1-B-1$ & 1 & 213843600 & 196712044 & -8.0 \\
\hline $1-B-2$ & 0.8 & 250683200 & 228350469 & -8.9 \\
\hline $1-B-3$ & 0.6 & 276210400 & 271386705 & -1.7 \\
\hline $1-B-4$ & 0.5 & 293778000 & 298498517 & 1.6 \\
\hline $1-B-5$ & 0 & 382925600 & 420322501 & 9.7 \\
\hline $1-C-1$ & 1 & 185008000 & 158696402 & -14.2 \\
\hline $1-C-2$ & 0.8 & 216705200 & 188852495 & -12.9 \\
\hline $1-C-3$ & 0.6 & 252602000 & 232262157 & -8.1 \\
\hline $1-C-4$ & 0.5 & 272165600 & 260017822 & -4.5 \\
\hline $1-C-5$ & 0 & 368044000 & 420390179 & 14.2 \\
\hline
\end{tabular}

Table 6. Analysis result of beams with a $4000 \mathrm{~mm}$ span

\begin{tabular}{|c|c|c|c|c|}
\hline Beam & $\begin{array}{c}\text { End } \\
\text { moment } \\
\text { Ratio }\end{array}$ & Collapse & DG-25 & $\begin{array}{c}\text { Difference } \\
{[\%]}\end{array}$ \\
\hline $2-A-1$ & 1 & 347162000 & 358732789 & 3.33 \\
\hline $2-A-2$ & 0.8 & 389045600 & 407908543 & 4.85 \\
\hline $2-A-3$ & 0.6 & 434292000 & 481429079 & 10.85 \\
\hline $2-A-4$ & 0.5 & 457244000 & 437994830 & -4.21 \\
\hline $2-A-5$ & 0 & 557056000 & 524090000 & -5.92 \\
\hline $2-B-1$ & 1 & 294443600 & 272090000 & $-7,59$ \\
\hline $2-B-2$ & 0.8 & 344190000 & 340112500 & -1.18 \\
\hline $2-B-3$ & 0.6 & 409880000 & 453483333 & 4.50 \\
\hline $2-B-4$ & 0.5 & 418188000 & 521441333 & 24.7 \\
\hline $2-B-5$ & 0 & 533516000 & 524090000 & 1.77 \\
\hline $2-C-1$ & 1 & 216802800 & 164840000 & -23.9 \\
\hline $2-C-2$ & 0.8 & 261571200 & 206050000 & -21.2 \\
\hline $2-C-3$ & 0.6 & 324888400 & 274680000 & -15.4 \\
\hline $2-C-4$ & 0.5 & 364371200 & 329680000 & -9.5 \\
\hline $2-C-5$ & 0 & 505964000 & 437100977 & -13.6 \\
\hline
\end{tabular}

\section{Discussion}

From Table 5, it can be seen that for beams with an 8000 mm span, most of the critical moments from the collapse analysis are close to the critical moment from DG-25. For beam with an $8000 \mathrm{~mm}$ span, elastic buckling formula governs the calculation of the critical moment and the results of collapse analysis also show that the stresses at peak load is still in elastic range. The difference of critical moments computed using the design guide and the collapse analysis is between $-14.2 \%$ to $18.3 \%$. The minus sign means that the DG-25 critical moment is less than critical moment in the collapse analysis. If it is assumed that the collapse analysis is the real one, minus sign means the DG- 25 is on the safe side. For Beams 1-A-5 and 1-C-5 the difference is high and not on the safe side.

From Table 6 , it can be seen that for beams with a $4000 \mathrm{~mm}$ span, the critical moment computed by the collapse analysis is generally greater than the critical moment of DG-25. The difference is between $-23.9 \%$ to
$24.7 \%$. There is only one beam that the critical moments of DG-25 is higher and not on the safe side. For beams with a $4000 \mathrm{~mm}$ span, inelastic buckling formula governs the calculation of the critical moment. The result of the collapse analysis also shows that the stresses at the peak load at the flange are in inelastic range.

It can be said that, the DG-25 is usually close to the collapse analysis and on the safe side, but sometimes it is higher and not on the safe side. Moreover the critical moment for the long beam using design guide is more accurate than for the short beam.

\section{Conclusion}

The collapse analysis have been made on a series of web-tapered beams and the conclusions drawn from this study are,

1. The critical moment for the long beam which is computed by elastic buckling formula of DG25 is usually close to the collapse analysis but sometimes it is higher and not on the safe side.

2. The critical moment for the long beam which is computed by DG25 is more accurate than the critical moment for the short beam.

The authors wish to thank Parahyangan Catholic University for its permission to use the licensed Adina Program.

\section{References}

1. D. Polyzois, I.G. Raftoyiannis, J. Of Struct. Eng. , 124, 1208-1216 (1998)

2. B.S. Miller, Thesis, Univ. of Pittsburgh, (2002)

3. J.S. Park, J. M. Stalling, J. Of Struct. Eng. , 129 1457-1465, (2003)

4. T. Vandermeulen, J.P. Jaspart, N. Boissonnade, $5^{\text {th }}$ Int.Conf. on Adv. In Steel Struct., Singapore, (2007).

5. L. Zhang, G. S., Tong, J. Constr. Steel Research, 64, 1379-1393, (2008)

6. I.G. Raftoyiannis, T. Adamakos, Op. Constr. And Build. Tech. J. E 4, 105-112, (2010)

7. M. Kovac, Procedia Engineering, 40 , 217-222, (2012).

8. Naaim N, F. De'nan, K.K. Choong, F. Azar, MAT. Web of Conf. , 47 (2016)

9. T. Patil, N.L. Shelke, J. Of Steel Struc. And Constr., 2 :2 (2016)

10. R.C. Kaehler, AISC Design Guide 25. (2011) 